\title{
Research on Advance of Rice False Smut Ustilaginoidea virens (Cooke) Takah Worldwide: IV. Identification of Rice Resistance to RFS, Management and Prospection of RFS
}

\author{
Shiwen Huang ${ }^{1,2}$, Lianmeng Liu ${ }^{1,3}$, Ling Wang ${ }^{1} \&$ Yuxuan Hou ${ }^{1}$ \\ ${ }^{1}$ State Key Laboratory of Rice Biology, China National Rice Research Institute, Hangzhou, China \\ ${ }^{2}$ Agricultural College, Guangxi University, Nanning, China \\ ${ }^{3}$ College of Plant Science and Technology, Huazhong Agricultural University, Wuhan, China \\ Correspondence: Shiwen Huang, State Key Laboratory of Rice Biology, China National Rice Research Institute, \\ Hangzhou 311401, Zhejiang, China. Tel: 86-133-8860-8130. E-mail: huangshiwen@caas.cn
}

Received: July 6, 2019 Accepted: August 9, $2019 \quad$ Online Published: September 15, 2019

doi:10.5539/jas.v11n15p275 URL: https://doi.org/10.5539/jas.v11n15p275

The research is financed by Shanghai municipality project "Agriculture through science and technology" (2019-02-08-00-08-F01127). The key $R$ \& D project of Zhejiang province (2019C02018); The National Key $R$ \& D Projects of China (2018YFD0200304, 2016YFD0200801); China-Norway international cooperation project: "CHN-2152, 14-0039 SINOGRAIN project II"; Innovation project of CAAS (CAAS-ASTIP-2013-CNRRI).

\begin{abstract}
Technological issues in identification of rice resistance were discussed in this part, including inoculum and its preparation, inoculation concentration of inoculum, inoculation time and method. It is very difficult to control RFS, RFS can only prevent but not cure, i.e., to control the RFS only spray fungicides before symptomatic appearance (rice smut balls appeared) can achieve better control efficiency, while once the smut ball appeared it could not be controlled even the concentration of fungicides increase several times, or spraying multiple times. Therefore, in order to achieve better control efficiency to RFS, integratd control measures need to be adopted. The integratd control measures including agricultural control, rice resistant varieties application, cultivation techniques, fertilization and water management, and fungicides application is the last approach and emergency measure for controlling RFS.
\end{abstract}

Keywords: RFS, resistance identification, identification technologies, accurate control techniques, prospection

\section{Introduction}

To obtain rice materials with true resistance to RFS is the basis and the key of success or failure for rice genetic resistance breeding to RFS. It is necessary to carry out the identification of rice varieties' (lines, materials) resistance to RFS. Scientific, reliable and standardized technologies of identification is the basis for screening out true resistance materials of rice. To establish the unified and standardized identification technology system for rice resistance to RFS is necessary. Technological issues in identification of rice resistance to RFS were discussed. Due to the difficulty to control RFS, and it only can prevent but not cure. Therefore, in order to achieve better control efficiency to RFS, integratd control measures need to be adopted. The integratd control measures including agricultural control, resistant varieties application, cultivation techniques, fertilization and water management, and fungicides are the last approach and emergency measures for controlling RFS. Precise timing of the optimum fungicide application time by "physical signs" of rice was presented, "one soaking and two spraying, timing by phyllula distance". "One soaking" means rice seeds soaked with fungicides for sterilization, "two spraying" means first spraying fungicides at 5-12 d before begin heading and begin heading, or 1-3 cm negative phyllula distance, or 1/3-1/2 rice plants in the field were at zero phyllula distance, the second spraying was at begin heading or 5-12 d after first spraying. The technology shows the characteristic of simple and convenient, easy to master, precision and high control efficiency. The authors' views of problems existing in research of RFS, as well as the research direction in the future, are put forward in this paper. 


\section{Identification of Rice Resistance to RFS}

Field testing is the closest to the natural conditions, and it is the main method to evaluate the resistance of rice varieties (Sonoda et al., 1992; Kurauchi et al., 2006). However, due to the fact that the field experiment consumed large amounts of time and man power; at same time, it was restricted by many factors, and the accuracy of the evaluation was affected, the repeatability of the test results was poor. Under controlled greenhouse conditions, artificial inoculation identification was employed, the efficiency was high and it could be repeated several times in a year. The results were accurate and the repeatability was good (Ashizawa et al., 2011). However, for the artificial inoculation under either natural conditions in the field (Zhang et al., 2003, 2004) or greenhouse of controlled conditions (Yang et al., 2011; Ashizawa et al., 2011; Hu et al., 2014), the identification of rice varieties' resistance to RFS was successful.

\subsection{Inoculum and the Preparation}

The chlamydospores, conidia, or conidia and mycelium fragments were used as the inocula for inoculation, which all could successfully induce RFS, and the effects of conidia and mycelium fragments were the best (Zhang et al., 2004; Yang et al., 2011; Ashizawa et al., 2011; Hu et al., 2014). At same time, the strains with strong pathogenicity, large sporulation and high germination rate of spores should be selected as inocula.

The inoculation effect of U.virens + potato sucrose broth (PSB) media as inocula was the best. The inoculation effect of the pathogen cultured in PSB for 5-7 d was good, but the inoculation effect was significantly decreased with the prolonging of the culture time. If the conidia concentration of the inocula was high, then the infected panicle rate and the diseased grain number was high. The PSB culture medium with a conidial concentration of 4 $\times 10^{6}$ spores $/ \mathrm{mL}$ was used for injection inoculation at middle and late booting stages of the susceptible variety, the incidence rate of panicle was $100 \%$, and the average number of the diseased grain was 35.1, with the highest number of 87 (Yang et al., 2011). Rice plants were inoculated with conidia and chlamydospores of $U$. virens, the disease index of inoculation with conidia was higher than that of chlamydospore in both the field and greenhouse (Zhang et al., 2004). There was also a report showing that the inoculation effect with conidia cultured for 3-4 days was good (Ashizawa et al., 2011), which was about 7 days shorter than that of the common culture time (Fujita et al. 1990a).

\subsection{Inoculation Concentration of Inoculum}

The resistance or susceptibility of rice varieties to RFS could be effectively differentiated when rice plants were inoculated with $5 \times 10^{5}$ conidia/mL suspension of $U$. virens (Fujita et al., 1990a, 1990b). The concentration of $7.5 \times 10^{5}$ conidia/mL could also identify the resistance level of rice varieties to RFS, but it would result in that $30 \%$ of susceptible varieties without heading. The concentration of $5 \times 10^{4}$ conidia/mL could not differentiate the varieties' resistance to RFS (Ashizawa et al., 2011). Increasing the dosage of inocula $(0.2,0.5,1$, and $2 \mathrm{ml}$ of a mixture of hyphae fragment and $2 \times 10^{6}$ conidia/ml suspension) caused more severe infections. There were small differences for different inoculation sites, for example, at the base, apex and mid of rice panicle. The optimum inoculation condition was 1-2 ml inoculum of hyphae fragment and $2 \times 10^{6}$ conidia/ml mixture suspension injected into the mid-point of rice panicle (Hu et al., 2014). If the concentrations of 1,2 and $4 \times 10^{6}$ conidia $/ \mathrm{mL}$ were used for inoculation, the average numbers of the diseased grain per panicle were $10.25 \pm 1.33$, $20.92 \pm 1.69$ and $24.38 \pm 2.05$, and the highest numbers of the diseased grains per panicle were 19,32 and 42 grains, respectively (Yang et al., 2011).

\subsection{Inoculation Time and Method}

\subsubsection{Inoculation Period}

Different rice varieties were artificially inoculated at different growth stages, the incidences of RFS were different. The experiments of nine times repetition in three years, it was proved that the rice plants during the young panicle formation period and middle booting stage was most vulnerable to be infected, and there was basically no infection after the heading stage (Chen et al., 1994). The comparative studies were conducted in greenhouse and field natural conditions. Rice plants were inoculated with chlamydospores and conidia, it was found that the RFS incidence of infected hills, panicles and grains during the booting stage inoculation were significantly higher than those of the begin heading and full heading stages, and also significantly higher than those of the control ( $\mathrm{Lu}$ et al., 1996). Therefore, to identify the rice varieties' resistance to RFS, the most suitable inoculation time was booting stage of rice. If the chlamydospores of U.virens stored at $-20^{\circ} \mathrm{C}$ for a long time and was used for injection inoculation, it could not cause RFS (Zhang et al., 2003), whereas the inoculation of the thin-wall conidia obtained from the potato sucrose liquid medium could cause diseases. The higher the concentration of spores, the higher of the infected panicle rate is. The inoculation performed at 6-9 d before 
begin heading stage, and the best inoculation time each day was 4-6 pm, the incidence of RFS was the highest. The addition of the potato juice into the suspension of inocula liquid could significantly increase the incidence of inoculation.

Identification of the rice growth stage by phyllula distance: The distance of phyllula here refers to the distance from the flag leaf phyllula to the phyllula of the next leaf (or the penult leaf, where the flag leaf is the last one). The susceptible variety "LYP9" was taken as an example, under room temperature conditions, the phyllula distance at the begin heading stage is $12-14 \mathrm{~cm}$ (the flag leaf phyllula is above $12-14 \mathrm{~cm}$ the penult leaf phyllula, it also called positive phyllula distance, the flag leaf phyllula is below he penult leaf phyllula, it was call negative phyllula distance) (Figure 1).

Inoculation with suspension of "conidia + mycelium fragments" was conducted at $0-13 \mathrm{~cm}$ of positive phyllula distance, or just begin heading stage of rice during booting period. When the inoculation periods were at $0-1,2-3$, 4-5, 6-7, 8-9, 10-11 and 12-13 cm (containing begin heading) of positive phyllula distance during the booting period, the average number of diseased grain per panicle were 5.42, 10.70, 16.81, 26.07, 35.10, 28.82 and 23.06. Among these, inoculation at 8-9 $\mathrm{cm}$ positive phyllula distance of rice booting period was the best effect of RFS incidence, and the highest diseased grain number reached up to 87. In the injection inoculation, if the positive phyllula distance is short, for example, the early and middle booting stages, the number of the diseased grains is less, the lower glume necrosis is easily caused, and it even affects the heading. Therefore, it was believed that the optimal injection inoculation stage for LYP9 was 8-9 $\mathrm{cm}$ positive phyllula distance, and the positive phyllula distance of 6-11 cm was appropriate, which is the middle to late booting stage of rice (Yang et al., 2011).

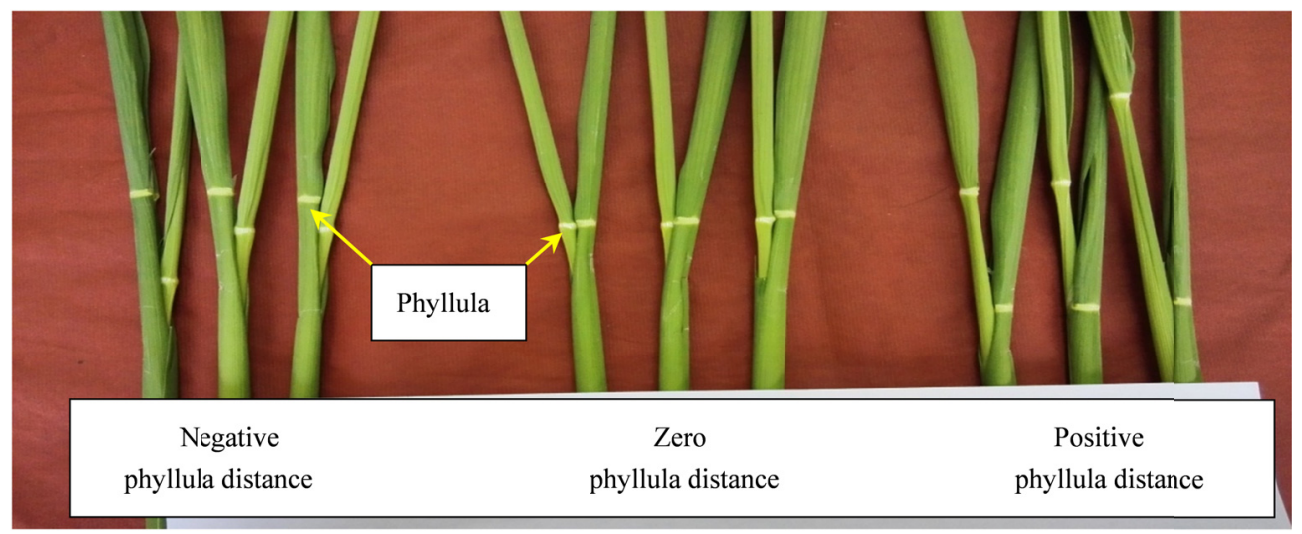

Figure 1. Sketch map of rice phyllula and phylulla distance

\subsubsection{Inoculation Method}

The artificial inoculation of RFS methods mainly include the injection method and the spraying method. Spraying inoculation with $U$. virens conidia suspension at 7-10 days before heading, it could identify the differences of varieties' resistance (Liao, 1993). Wang et al. (1996) believed that the best effect was injection inoculation with chlamydospore, followed by spray inoculation. Rice plants were inoculated with $U$. virens conidia suspension by using injection and spray method during booting stage and heading stage, both of which could induce RFS on rice. However, the injection inoculation easily caused rice panicle deformity or heading difficulties, which needs to be improved ( $\mathrm{Li}, 1996)$. The research results of $\mathrm{Lu}$ et al. (1996) showed that the incidence of the conidia inoculation method at booting stage was the highest. It was higher than that of the chlamydospore inoculation no matter in the field or greenhouse, and the incidence of the injection inoculation was higher than that of spray inoculation for the same inocula. The incidence of RFS was higher when spray inoculation with conidia suspension at rice heading stages and preserve moisture. The conidia or chlamydospores of $U$. virens were used as inocula, the incidence of the same inocula by injection inoculation method was higher than that of the spraying inoculation both in the field and indoor. The incidence of RFS reached up to $100 \%$, the highest disease index was 93.96, and the number of diseased grains per panicle reached up to 110 . The inoculation technique could distinguish the resistances differences of rice varieties Dai et al. (2005). 


\section{Management of RFS}

At present, the management of RFS basically adopt the strategy of "prevention first, integrated management". Agricultural management was the basis and chemical control used as assistance or the emergency measures. The rice varieties with resistance (tolerance) to RFS should be planted, and seeds sterilization and field management should be done very well. Rice production practice have proven that the RFS could only be prevention but could not be treated. It was very important to choose the optimum rice growth stage for chemical application and select special agents in order to obtain better protective effect. The treatment effect is very poor (limited tiny) even spraying multiple with high concentration fungicide once the appearance of smut ball of RFS. Biological control is becoming a hot topic gradually, and it will likely be the development trend in the future.

\subsection{Agricultural Control}

According to the description of "Conditions affecting incidence of RFS" in part III, the targeted farming operation should be carried out, which has a good auxiliary effect on the prevention and control of RFS.

\subsubsection{Resistance of Varieties}

Different rice varieties have significant differences in the resistance responses to RFS. Selecting and planting resistant (tolerant) rice varieties is the most economic and effective measures for prevention and control of RFS, and the susceptible varieties need to be eliminated in rice production practice.

\subsubsection{Cultivation Techniques}

The early maturing (or short growth duration), short tillering and booting stage of rice varieties should be selected and/or sowing and planting time need to be adjusted according to the rice planting areas, so that the sensitive or KGSR (the late booting to heading stage) could avoid local climate conditions which was favorable the occurrence of RFS, and could reduce the incidence of RFS (Yashoda et al., 2000; Dodan et al., 1995). Rational close planting, for example, the wide row and short distance of hills planting pattern should be used. Rice seeds from the infected areas should be avoided, and the infected rice plants should be removed early in order to eliminate the primary infection source to avoid the spread of RFS. Sclerotia of $U$. virens need to be pick out and deeply buried or burned, plough and bask the field should be carried out after harvesting in the RFS occurred areas, and timely sowing and transplanting.

\subsubsection{Fertilization and Water Management}

Fertilization technology should be improved, N, P, K fertilizers should be applied reasonably. Most of the fertilizer should be applied in early growth stage of rice for promoting tillering, and less fertilizer should be used in the late growth stages of rice. Panicle fertilizer, especially $\mathrm{N}$ fertilizer, should be used modestly. The dosage of potassium fertilizer and organic fertilizer should be increased due to they could increase the resistance of rice varieties. Based on the "edge effect" of RFS, only a small amount of fertilization should be used at the edges of the field.

Water management should be conducted scientifically, and intermittent irrigation methods should be used to keep the paddy field dry and moisture alternative. The specific procedures were as follows: shallow water transplanting, deep water $(3-5 \mathrm{~cm})$ for protecting the seedlings, tiller seedlings with 2-3 cm deep of water. If the seedlings were enough and the field drying was needed. Keeping the paddy field dry and wet alternating in the late rice growing stage (Bhagat et al., 1999).

\subsection{Chemical Control}

RFS can be prevented and controlled by fungicides (Ahonsi et al., 2002; Tsuda et al., 2006), but it has been very difficult to forecast the epidemics of RFS due to no consistent correlation has been established between environmental factors, development of the U. virens, susceptibility of rice cultivars and RFS. Consequently, chemical control of RFS is ineffective because farmers usually cannot predict when they should spray fungicides before symptoms (smut ball) emerge, whereas it is too late to spray chemicals after symptoms have appeared. Therefore, identification of favorable alleles and improvement of rice resistance to RFS would be a cost-effective and practical strategy (Zhou et al., 2014). The application of chemicals is an effective and emergency measure for prevention and control of RFS, and the key factor for obtaining good control effect is "selection of specific fungicides, and determining the optimum time or KGSR to apply fungicides".

\subsubsection{Seed Treatments}

Before sowing, rice seeds without disease should be selected, and seed disinfection need to be conducted. It can reduce the quantity of the $U$. virens in seeds and reduce the occurrence of RFS. The diseased seeds were treated with seed disinfectant, and the preventive effect on RFS was 70.0-90.5\%. Different reagents were used for 
soaking seeds for $48 \mathrm{~h}$, and the effect orders was as follows: bayleton > thiophanate methyl > pentachloronitrobenzene $>$ carbendazim, but none of these could completely prevent the occurrence of RFS (Li, 1996).

\subsubsection{Control Practice of RFS}

Selection of fungicides: A large number of experiments on $U$. virens in indoor and RFS in paddy fields were carried out by Chinese and foreign scholars, and numerous of fungicides with good inhibition and control efficiency on U. virens/RFS have screened out (Hegde et al., 2000; Singh et al., 2002; Ahonsi et al., 2003; Sehly et al., 2004). The indoor tests demonstrated that prochloraz, difenoconazole, propiconazole and tebuconazole had good inhibitory effects on $U$. virens, and the average $\mathrm{EC}_{50}$ values were $0.32 \pm 0.08,0.45 \pm 0.08,0.19 \pm 0.03$ and $0.21 \pm 0.06 \mu \mathrm{g} \mathrm{mL}^{-1}$, respectively. The inhibitory effects of the fungicides trifloxystrobin, picoxystrobin, azoxystrobin on mycelium were strong, and the $\mathrm{EC}_{50}$ values were $0.0328,0.0826$ and $0.1001 \mu \mathrm{g} \mathrm{mL} \mathrm{m}^{-1}$, respectively. The synergism effect of the difenoconazole and jinggangmycin A mixed at a ratio of 1:2 was very significant, the toxicity coefficient of mixture was 174.8 , and the $\mathrm{EC}_{50}$ value was $0.2263 \mu \mathrm{g} \mathrm{mL}^{-1}$. The field control effects of $43 \%$ tebuconazole SC, $25 \%$ azoxystrobin SC, $25 \%$ prochloraz EC, $8 \%$ validamycin A $+4 \%$ difenoconazole WP and 25\% propiconazole EC were $83.27 \%, 82.8 \%, 82.7 \%, 80.7 \%$ and $80.3 \%$, respectively (Ruan et al., 2013).

$50 \%$ propiconazole EC at $300 \mathrm{~g}$ a.i./ha was first applied at 10 days before begin heading of rice, then $10 \mathrm{~d}$ later a second application was carried out. The control efficiency on RFS of two years' were $71.5 \%$ to $74.3 \%$ (Chen et al., 2013). The results of the paddy experiments showed that the following chemicals had a good control efficiency on RFS: 30\% difenoconazole propiconazole (Armure) EC and 12.5\% diniconazole (Hu et al., 2010; Zhang et al., 2010); 12.5\% epoxiconazole suspension agent (Wang, 2013; He et al., 2013); 27.12\% basic copper sulfate suspension (Zhang et al., 2012; Zhou et al., 2013); 25\% difenoconazole EC (Wei et al., 2009; He et al., 2013); 50\% kresoxim-methyl suspension, and MJ2006 (prochloraz + validamycin compound) (Zhang et al., 2010).

Fungicides application frequency and time or rice growth period: Some scholars believed that three times application of fungicides could achieve the best control efficiency for RFS, which were applied in the late tillering stage, 3-7 d before begin heading stage, and the begin heading stage, respectively (Hu et al., 2010; Li et al., 2012), but some scholars believed that the control effect of two times applications of fungicides was also very good, namely 5-7 d before begin heading and full heading stage (Li et al., 2013a; Luo et al., 2013; Liu et al., 2013). For example, $250 \mathrm{~g} / \mathrm{L}$ Azoxystrobin $\mathrm{SC}$ was sprayed at $7 \mathrm{~d}$ before begin heading and begin heading stage, the control effects for both the infected panicle rate and of disease index were $92.31 \%$. Compared with the control efficiency of one time application of fungicide at $7 \mathrm{~d}$ before begin heading $(80.8 \%$ and $86.5 \%$, respectively), there was no significant difference. However, there were significant differences of control efficiency compared with that one time application of fungicide at heading period $(42.31 \%$ and 55.77 , respectively) (Zhou et al., 2013). For some rice varieties, the control effects were also very good for one time application of fungicides at 7-10 d before begin heading stage and during the heading period (Guo, 2013), or about $10 \mathrm{~d}$ before heading stage for the first time of chemicals application, and ten days later, a second application was carried out (Chen et al., 2013).

Japanese scholars used simeconazole granules (450-600 g a.i./ha) in a submerged application two to five weeks before heading was also highly effective against false smut, with treatment three weeks before heading being the most effective. The results also showed that the application of flusilazole at two to three weeks before heading could effectively control the panicle blight in the rice heading stage, RFS, rice kernel smut and sheath blight (Rhizoctonia solani) (Tsuda et al., 2006).

Precise timing of the optimum fungicide application time by "physical signs" of rice: It was difficulty for accurately determining the number of "days" before heading, especially for ordinary rice farmers, so it is very difficult to accurately grasp the optimum time for actual operations in the field. In addition, the growth process of rice was also associated with the rice varieties, climatic conditions and rice growth status. Rice physical signs here refer to phyllula, "the same level of phyllula, or "zero distance of phyllula, or distance of phyllula" of rice, Figure 1, i.e., the phyllula of flag leaf and penult leaf hold the same level (the flag leaf is tailender leaf), which are equivalent to those of 5-12 d (there are differences among different varieties) before begin heading (Dong et al., 2004). If only one time application of fungicides, a better control efficiency for susceptible indica/japonica hybrid rice variety "Yongyou 12" can be acquired from the spraying at 10-12 d before begin heading (the physiological indicator of 10-12 d before begin heading of "Yongyou 12" was "Yezhenping", means zero distance of phyllula, the days of 10-12 determine by the climate conditions of this period of rice growing. The 
days from zero distance of phyllula to begin heading there were differences among the different types of rice varieties, which were generally in the range of 5-12 d (Xu et al., 2005). After several years continuous experiments in the paddy field, a technology of "one soaking and two spraying, timing by phyllula distance" was developed. "One soaking" means rice seeds soaked with fungicides for sterillzation, "two spraying" means first spraying chemicals at 5-12 d (the days of different rice varieties are different) before begin heading and begin heading, or 1-3 cm negative phyllula distance, or 1/3-1/2 rice plants were at zero phyllula distance, the second spraying was at begin heading (5-10\% rice plants heading) or 5-12 $\mathrm{d}$ after first spraying. The technology shows the characteristic of simple and convenient, easy to master, precision and high control efficiency (Rao et al., 2019).

\subsection{Biological Control}

Due to the limitations of chemical control, the biological control of RFS is the future direction of development. Antibiotics, antagonistic bacteria and plant source preparations have become research hot field in recent years (Liu et al., 2004). The prevention and control of RFS by means of antibiotics have been used for many years, and the most widely used agent is Jinggangmycin. The control effect of Jinggangmycin either alone or mixed with carbendazim was good ( $\mathrm{Li}$ et al., 1990; Zhu et al., 1996). Wang et al. (2003) performed indoor and outdoor experiments on RFS with Ningnanmycin, and the indoor antibacterial effect was $67 \%$, but the average spike control effect in the field was only $36.4 \%$. The currently available biocontrol agents mixture, for example, Jinggangmycin and Bacillus mixture have been used in large production areas for the control of RFS, and good control effects have been achieved (Chen et al., 2003; Cai et al., 2011; Chen et al., 2011).

Antimicrobial microorganisms have been isolated from RFS ball (Xu, 2002). $A_{1}$ and $\mathrm{H}-51$ are two good strains among 114 bacteria isolated from paddy soil (Lan et al., 2004), the fermentation liquid of $\mathrm{A}_{1}$ and $\mathrm{H}-51$ had a good inhibition rates on mycelium growth, and conidia germination of $U$. virens. 1800 bacterial isolates were isolated from the soil, among which SF-62 and SF-3-38 of Bacillus subtilis grew quickly, and had a strong inhibition effect on the growth of $U$. virens, the inhibition rates reached $97.2 \%$ and $85.9 \%$, respectively (Yin et al., 2011). The extract of some types of actinomycetes fermentation also could inhibit the growth of $U$. virens (Huang et al., 2000). All of the strains showed potential for the development of the biocontrol agents of RFS.

Some scholars have attempted to study and use plant extracts to control RFS. $10 \%$ mint extract had an inhibition rate of $100 \%$ on the germination of conidia, chlamydospores of $U$. virens, it could significantly inhibit the mycelial growth and cause variation of clony, which has a value for in-depth research and development (Jin et al., 2005).

Recently, it was found that some species of Trichoderma had a strong inhibitory effect on $U$. virens, which have potential to be developed into biocontrol agents (Ashish et al., 2014). Gliotoxin what secreted by Trichoderma virens strain TY009 could completely inhibit the conidia germination and formation of secondary spores of $U$. virens at a concentration of $1.0 \mu \mathrm{g} \mathrm{mL}^{-1}$ (Liu et al., 2010). Some viruses was isolated from chlamydospores (Zhang et al., 2013; Zhong et al., 2014; Jiang et al., 2014) and show some inhibition on $U$. virens, however, whether or not these viruses can be used as the virus agent need to be further studied (Yu et al., 2010).

\section{Problems and Prospects}

Rice false smut frequently and seriously occurred in rice production worldwide, and the damage both rice yield and grain quality caused by it is very serious. The relevant departments of the Chinese government and researchers pay high attention to this issue, and have also invested large amounts of manpower, financial resources and material resources in carrying out the basic research and development of prevention and control technologies. However, up to now, the life history of $U$. virens, its mechanism of infection, the interaction characteristic of the $U$. virens-host (rice) and other major basic theory problems have been not very clear or have no unified conclusion. There are key points need to be solved in the management technology of RFS, of which the infection mechanism of $U$. virens, including infection period, infection site, source of the pathogen, and its expansion pattern and other problems have been controversial (Gao et al., 2011).

The reports regarding the host range of $U$. virens are rare scientific results, and there is still lack of a systematic investigation. The pathogenicity variation of the pathogen and its molecular mechanism remain unclear, and the research regarding the mechanism of host and pathogen interaction, recognition and signal transduction in cells of rice, and rice defense response gene activation process are relatively weak (Zou et al., 2012).

Due to no uniform standards of the identification technology of rice resistance to RFS, the results of rice resistance to RFS obtained by different researchers are not consistent, not stable and the repeatability is poor, the results of different researchers unable to be compared. Recognized resistant materials of rice are not obtained in 
screening, and the genetic breeding of rice with resistance to RFS has yet not to be carried out. Therefore, a technology system of artificial inoculation and identification of rice resistance to RFS should be established and improved as soon as possible. The standardized inoculation and identification can be carried out under controlled conditions. The resistant materials of rice could be screened out and provided guarantee for the breeding of rice resistance to RFS.

The use of ustiloxins produced by $U$. virens for simple and rapid screening of rice resistant materials is worthy of further research and development. Combination of molecular biology and genetic engineering to specifically confirm whether the rice resistance to RFS is the real genetic resistance or plant morphology or external environment influence are the pressing matters at present.

RFS primary infection sources, secondary infection source, infection period and location, infection pathway, pathogenic mechanism, cycle of infection and pathogen-host interaction require further clarification. The research and cloning of important genes related to $U$. virens pathogenicity by infection and virulence variation, along with a clear understanding of the genome and establishment of a genetic transformation system of mature pathogen. RNA interference, gene knockout method and other methods and techniques of reverse genetics should be used to establish some rice false smut pathogens ( $U$. virens) mutants. The functional genomics and proteomics research methods should be employed in order to isolate and clone rice resistance genes to elucidate the mechanism of pathogenesis of $U$. virens from the molecular level. We studied on the interaction between RFS and rice, the regulatory mechanism of signal transduction of pathogenic elicitor and activation process of defense response genes, and establishing rice germplasm resources with resistances to RFS through the transgenic technology and breeding new varieties with lasting resistance to RFS.

The selection of the proper fungicides and precise timing to determine the optimal time of chemicals application is the key to increase the efficiency of the chemical control on RFS. Presently, the control effect for twice application of chemicals was the best: first application of fungicides was at 5-7 d before begin heading, and second time application was at heading stage, or second time application of the fungicide at 7-10 d after the first time application. In practical operation, it is difficult to accurately define the first time application of 5-7 d before begin heading or 7-10 d before the heading. Furthermore, different rice varieties with different weather conditions in the growth period (late booting to heading stage), different fertilization and water management, and different rice growth status and so on, all could affect the duration of the "late booting period and heading period".

The "physical signs" method is used for precise timing of fungicide application to control RFS, namely the first time of chemical spraying should be carried out at phyllula in the same level (or zero distance between pulvinus) (i.e., 5-7 $\mathrm{d}$ or 7-10 $\mathrm{d}$ before begin heading, and different rice varieties are different) of flag leaf and the penult leaf of most rice plants. The second time application of chemicals should be at begin heading stage of the most plants. The method of timing and fungicide application could achieve a better control effect on RFS.

\section{References}

Ahonsi, M. O., \& Adeoti, A. A. (2002). False Smut on upland rice in eight rice producing locations of Edo State, Nigeria. J of Sustainable Agri, 20(3), 81-94. https://doi.org/10.1300/J064v20n03_08

Ahonsi, M. O., \& Adeoti, A. A. (2003). Evaluation of fungicides for the control of false smut of rice caused by Ustilaginoidea virens (Cooke) Tak. Moor J of Agri Res, 4(1), 118-122. https://doi.org/10.4314/mjar.v4i1. 31764

An, S., Li, M., \& Ma, X. (2014). Control efficiency to rice sheath blight and false smut of prochloraz manganese salt difenoconazole. Zhejiang Agri Sci, 1, 76-77.

Ashish, K., Sahu, T. K., Atul, B., \& Shivcharan, S. (2014). Influence of Trichoderma spp. Against Ustilaginoidea virens inciting false smut of rice. Environment and Ecology, 32(1), 163-168.

Ashizawa, T., Takahashi, M., Moriwaki, J., \& Hirayae, K. (2011). A refined inoculation method to evaluate false smut resistance in rice. J Gen Plant Pathol (Fungal Diseases), 77, 10-16. https://doi.org/ 10.1007/s10327-010-0279-5

Bhagat, A. P., \& Prasad, Y. (1999). Effect of irrigation on incidence of false smut of rice. J of Applied Biol, $6(1-2), 131-132$.

Cai, G., \& Li, J. (2011). Pharmacodynamic test of 10\% Jinggangmycin bacillus cereus suspending agent to control rices heath blight. Anhui Agri Sci Bull, 17(05), 101-102. 
Chen, F., Deng, F., Liu, J., Deng, W., \& Yang, J. (2011). Experiments of rice false smut and sheath blight management by using mixture of bacillus subtilis and Jinggangmycin. Jiangxi Plant Protection, 34(4), 177-178.

Chen, Y., Xiao, Y., \& Zhao, Y. (1994). Studies on the main period of false smut pathogen (Ustilaginoidea virens) invades rice. Hubei Agri Sci, 1, 24-26.

Chen, Y., Zhang, Y., Yao, J., Li, Y., Yang, X., Wang, W., ... Gao, T. (2013). Frequency distribution of sensitivity of Ustilaginoidea virens to four EBI fungicides, prochloraz, difenoconazole, propiconazole and tebuconazole, and their efficacy in controlling rice false smut in Anhui province of China. Phytoparasitica, 41, 277-284. https://doi.org/10.1007/s12600-013-0288-y

Chen, Z., Lu, F., Liu, Y., Yang, X., \& Liu, Y. (2003). Develop and industrialization of microorganism fungicide for control of rice diseases-wenquning. Jiangsu J of Agri Sci, 19(2), 108.

Dai, G., Zhao, J., He, R., Jin, S., \& Nicole, M. (2005). Histochemical observation on the resistant and susceptible varieties to Ustilaginoidea virens (Cooke) Tak and the way of infection of conidia. Acta Phytopathologica Sinica, 35(1), 37-42.

Dodan, D. S., \& Ram, S. (1995). Eeffec of planting time on the incidence of blast and false smut of rice in Haryana. Indian Phytopathology, 48(2), 185-186.

Dong, H., Li, D., Xu, G., \& Zhang, Q. (2004). Probe into the invasion period and control technology of rice false smut (Ustilaginoidea virens). Zhejiang Agri Sci, 3, 153-154.

Fujita, Y., Sonoda, R., \& Yaegashi, H. (1989). Inoculation with conidiospores of false smut fungi to rice panicles at booting stage. Annals of the Phytopathological Society of Japan, 55(5), 629-634. https://doi.org/ 10.3186/jjphytopath.55.629

Fujita, Y., Sonoda, R., \& Yaegashi, H. (1990a). An improved method for conidial formation of false smut fungus Ann Rept Soc Plant Prot North Jpn, 41, 35-36.

Fujita, Y., Sonoda, R., \& Yaegashi, H. (1990b). Evaluation of the false smut resistance in rice. Ann Rept Plant Prot North Jpn, 41, 205.

Gao, B., \& Zhong, J. (2011). Research advances in infection processof Ustilaginoiden virens. Hunan Agri Sci, 3, 93-97. https://doi.org/10.4028/www.scientific.net/AMR.383-390.93

Gao, T., \& Liao, R. (2003). Control efficiency of rice false smut sprying “Quwenling” by using different sprayer. Proceedings of Symposium of East China Phytopathology Society and $10^{\text {th }}$ Members Representative Conference of Jiangsu Provincial Phytopathology Society, 2003 (p. 475).

Guo, C. (2013). Effect of chemicals application stage and frequency on the control efficiency to rice false smut. Anhui Agri Sci Bull, 19(01-02), 80-81.

He, H., Tang, Q., Chen, X., Wu, S., Yang, X., Yuan, J., \& Wang, L. (2013). Evaluation of control efficiency to rice false smut (Ustilaginoidea virens) of different fungicides. Anhui Agri Sci Bull, 19(17), 76-77.

Hegde, Y., Anahosur, K. H., \& Srikant, K. (2000). Chemical control of false smut of rice caused by Claviceps oryzae sativae Hashioka. Karnataka J of Agri Sci, 13(3), 623-627.

Hu, G., Pan, C., Pan, H., Zhu, G., \& Ding, X. (2010). Studies on the causes of rice false smut serious occurrence and key technology of chemicals control. Anhui Agri Sci Bull, 16(5), 98-100.

Hu, M., Luo, L., Wang, S., Liu, Y., \& Li, J. (2014). Infection processes of Ustilaginoidea virens during artificial inoculation of rice panicles. Eur J Plant Pathol, 139, 67-77. https://doi.org/10.1007/s10658-013-0364-7

Huang, S., \& Yu, L. (2000). Study on the pests biological control of Streptomyces lavendulo- hygtroscopicus and its ultraviolet radiation induced strain. J of Agri Biotech, 8(1), 79-84.

Jiang, Y., Luo, C., Jiang, D., Li, G., \& Huang, J. (2014). The complete genomic sequence of a second novel partitivirus infecting Ustilaginoidea virens. Arch Virol, 159, 1865-1868. https://doi.org/10.1007/ s00705-014-1991-9

Jin, S., Qian, Q., Dai, G., \& Xue, H. (2005b). Inhibition of extracts of Menthe arvensis and Euphorbia helioswpia to Ustilaginoidea virens. J of Shanghai Jiaotong Univ (Agri Sci), 23(1), 92-94.

Kurauchi, K., Kudo, Y., Kimura, T., \& Uemura, T. (2006). Difference in resistance to false smut disease between rice cultivars in Aomori prefecture. Ann Rept Plant Prot North Jpn, 57, 17-21. 
Lai, G. (2007). Preliminary report on the control efficacy of 30\% Armure to rice false smut. Fujian Rice and Wheat Sci \& Tech, 25(1), 15-16.

Lan, S., \& Chen, H. (2004). Screening of the antagonistic bacteria of Ustilaginoidea virens and its antibiotic activity. Plant Protection, 30(2), 69-72.

Li, J., \& Chu, M. (2013a). Studies of control efficiency of $75 \%$ Nativo water dispersible granule on neck blast and false smut. Modern Agri Sci and Tech (Plant Protection), 2, 138-142.

Li, Q., \& Huang, Y. (1990). Experiment of rice false smut control with Chemicals. Guangxi Agri Sci, 5, 26-29.

Li, W., Su, J., \& Fan, G. (2013b). Control effects of three fungicides on sheath blight, rice false smut and ri ce blast in Field testing. Biological Disaster Science, 36(2), 174-177.

$\mathrm{Li}, \mathrm{X}$. (1996). Rice false smut control by seeds treating with chemicals and identification of rice varieties' resistance to Ustilaginoidea virens. J of Anhui Agri Sci, 24(3), 245-248.

Li, Z., \& Zhou, X. (2012). Application of Nativo in rice diseases management of rice whole growth stage. China Plant Protection, 32(6), 51-53.

Liao, Q. (1993). Studies on evaluation technique for the varietal resistance to seed-borne rice false smut. $J$ of Yunnan Agri Univ, 8(3), 209-212.

Liu, L., Tu, Y., \& Zhang, J. (2010b). Biocontrol potential of Trichoderma virens strain TY009 against rice sheath blight and other main fungal diseases. Scientia Agricultura Sinic, 43(10), 2031-2038.

Liu, Y., Chen, Z., Lu, F., \& Liu, Y. (2004). Study on controlling rice false smut. J of Jinlin Institute of Tech, 20(3), 42-45.

Liu, Y., Sang, H., Wang, J., Yu, Y., Song, C., Ma, X., \& Yu, S. (2013). Study on the optimum application period of trifloxystrobin tebuconazole $75 \% \mathrm{WG}$ against main rice diseases in coastal region. World Pesticide, 35(3), 59-61.

Lu, F., Chen, Z., Chen, Y., Shi, A., Wang, F., \& Zhang, H. (1996). Studies on biological characters and some uncertain key point relation to infection cycle of rice false smut. Jiangsu J of Agri Sci, 12(4), 35-40.

Luo, H., Wang, H., \& Fu, H. (2013). A preliminary report of trifloxystrobin-tebueonazole in rice false smut control and its application technology. Biological Disaster Science, 36(3), 295-297.

Rao, H., Luo, H., Shi, T., Li, Y., \& Huang, S. (2019). Investigation of Heading Dynamic States of Yongyou 12 and Optimal Time to Spray Chemicals for Prevention Rice False Smut. China Rice, 25(1), 74-79.

Ruan, H., Yang, X., Shi, N., Du, Y., Gan, L., \& Chen, F. (2013). Toxicity and field efficiency of several fungicides against Ustilaginoidea virens. Fujian J of Agri Sci, 28(6), 580-583.

Sehly, M. R., Osman, Z. H., \& Salem, E. A. (2004). Chemical control of rice false smut disease in Egypt. Egyptian J of Agri Res, 82(1), 263-272.

Singh, R., Dodan, D. S., \& Sunder, S. (2002). Efficacy of fungi toxicants against false smut of paddy. Haryana AgriUniv J of Res, 32(2), 89-90.

Sonoda, R., Fujita, Y., \& Yaegashi, H. (1992). Varietal difference in resistance of rice to false smut. Ann Phytopathol Soc Jpn, 58, 561-562.

Tsuda, M., Sasahara, M., Ohara, T., \& Kato, S. (2006). Optimal application timing of simeconazole granules for control of rice kernel smut and false smut. J Gen Plant Pathol, 72, 301-304. https://doi.org/10.1007/ s10327-006-0288-6

Wang, D., Dong, H., Yang, H., Xu, W., \& Liu, F. (2003). Preliminary report of several fungicides control effect on rice false smut. Liaoning Agri Sci, 5, 47-48.

Wang, P. (2012). Efficacy Study of 30\% mancozeb oil suspension against rice sheath blight and rice false smut. Modern Agri Sci and Tech, 24, 136-138.

Wang, S., Bai, Y. J., Liu, X. Z., Zhu, M. S., Guo, X. B., \& Jiang, K. P. (1996). Studies on the inoculums and inoculation methods of rice false smut. Liaoning Agri Sci, 1, 33-35.

Wang, X. (2013). Studies of the control efficacy of $12.5 \%$ epoxiconazole suspending agent on rice false smu (Ustilaginoidea virens). Modern Agri Sci \& Tech, 5, 144. 
Wei, G., Zhou, B., Zhou, Y., Zhu, F., \& Wei, M. (2009). Experiments of $25 \%$ difenoconazole EC to control rice sheath blight (Rhizoctonia solani) and rice false smut (Ustilaginoidea virens). Modem Agrochemicals, 8(2), 51-53.

Xu, C. (2002). Dynamic change of antagonisms bacteria in the plants of different main cultivar and management of rice false smut (Ustilaginoidea virens) (Master Thesis, Zhejiang University, China).

Xu, M., Chen, Y., Zhou, Y., \& Jin, Z. (2005). First exploration of control strategies and suitable period for rice false smut (Ustilaginoidea virens). Acta Agriculturae Zhejiangensis, 17(3), 161-162.

Yang, X., Wang, S., Ruan, H., Shi, N., Gan, L., \& Chen, F. (2011). Artificial inoculation techniques of rice false smut in greenhouse. Acta Phytophylacica Sinica, 38(5), 395-400.

Yashoda, H., \& Anahosur, K. H. (2000b). Effect of date of sowing on the incidence of false smut of rice. Advances in Agri Res in India, 14, 147-149.

Yin, X., Chen, Z., Liu, Y., Liu, Y., Wang, X., Luo, C., ... Nie, Y. (2011). Screening and evaluation of antagonistic bacteria against ricef alse smut. Jiangsu J of Agri Sci, 27(5), 983-989.

Yu, X., Li, B., F, Y., Jiang, D., Said, A. G., Li, G., ... Yi, X. (2010). A geminivirus-related DNA mycovirus that confers hypovirulence to a plant pathogenic fungus. Proc Natl Acad Sci USA, 107(18), 8387-92. https://doi.org/10.1073/pnas.0913535107

Zhang, J., Chen, Z., Zhang, B., Liu, Y., \& Lu, F. (2004). Inoculation techniques used for inducing Rice false smut efficiently. Acta Phytopathologica Sinica, 34(5), 463-467.

Zhang, J., Zhang, B., Chen, Z., Liu, Y., \& Lu, F. (2003). Preliminary study on inoculation method of rice false smut and its effect. Chinese J Rice Sci, 17(4), 390-392.

Zhang, T., Jiang, Y., Huang, J., \& Dong, W. (2013). Genomic organization of a novel partitivirus from the phytopathogenic fungus Ustilaginoidea virens. Arch Virol, 158, 2415-2419. https://doi.org/10.1007/ s00705-013-1742-3

Zhang, Y., Shi, X., Cai, J., Liu, W., \& Zhang, Y. (2012). Studies of different application period of $27.12 \%$ basic chrome sulphate suspending agent on control efficacy for rice false smut. Modern Agri Sci and Tech, 11, 116-119.

Zhang, Z., Chai, R., Chen, G., \& Wang, Y. (2010). Experiment of control efficacy of several fungicides to rice false smut Ustilaginoidea virens. Zhejiang Agri Sci, 6, 1328-1329.

Zhong, J., Zhou, Q., Lei, X., Chen, D., Shang, H., \& Zhu, H. (2014). The nucleotide sequence and genome organization of two victoriviruses from the rice false smut fungus Ustilaginoidea virens. Virus Genes, 48, 570-573. https://doi.org/10.1007/s11262-014-1050-3

Zhou, F., Geng, Y., Xu, L., Kang, X., Chen, Y., \& Yuan, L. (2013). Study on controlling Ustilaginoidea virens with 6 fungicides on different application period. Modem Agrochemicals, 12(5), 54-56.

Zhou, Y. L., Xie, X. W., Zhang, F., Wang, S., Liu, X. Z., Zhu, L. H., ... Li, Z. K. (2014). Detection of quantitative resistance loci associated with resistance to rice false smut (Ustilaginoidea virens) using introgression lines. Plant Pathol, 63(2), 365-372. https://doi.org/10.1111/ppa.12091

Zhu, R., Gu, A., Zhang, K., Huang, Z., \& Tang, W. (2011). Experimental study of $12.5 \%$ epoxiconazole suspending agent on controlling sheath blight and false smut of rice. Modern Agri Sci and Tech, 4, 147-149.

Zhu, W., \& Xiao, Y. (1996). Preliminary study on chemicals control of rice false smut. Hubei Agri Sci, 1, 41-43.

Zou, K., Hu, D., Wang, W., \& Xu, X. (2012). Research progress of rice false smut (Ustilaginoidea virens). Zhejiang Agri Sci, 5, 704-706.

\section{Copyrights}

Copyright for this article is retained by the author(s), with first publication rights granted to the journal.

This is an open-access article distributed under the terms and conditions of the Creative Commons Attribution license (http://creativecommons.org/licenses/by/4.0/). 